\title{
Café cubano à la Grisel
}

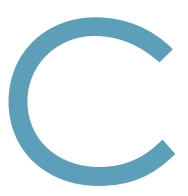

UBAN COFFEE is generally made in an Italian-style coffee pot or an espresso machine. If one chooses the latter, you add the sugar after the coffee is strained. You can also prepare it the traditional way. Boil water with sugar. Once it is boiling, add the coffee and keep boiling it for another minute (taking care that it does not boil over). Lower the flame and let it sit for a minute; and then you strain the mixture thru a colador, or strainer (which looks like a sock with a metal hoop at the top). When you strain the coffee this way, it is café carretero, which was common before the appearance of Italian coffee makers. You can serve it as espresso or cut the café with a small amount of hot milk, making it a cortadito. You can use either cow's milk or evaporated milk.

You can also skip the sugar at the beginning of the process and add condensed milk to taste. In this instance, your café becomes un café cortado con leche condensada (a short coffee with condensed milk). If you add a whole cup of milk, then you have the typical Cuban café con leche (coffee with milk).

Yet another way to serve café is to add a thin lemon peel, giving it an entirely different taste altogether. You can also add a splash of cognac just as you are about to serve the café. This would make it un carajillo. You can also serve it with a splash of anis. 


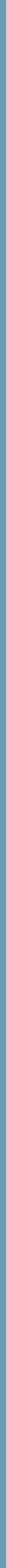


CUBAN ARTISTS ACROSS THE DIASPORA 
This page intentionally left blank. 